THE DEVELOPMENT OF ENVIRONMENTAL MORAL IDENTITY

Peter H. Kahn, Jr.

University of Washington

To appear in S. Clayton and S. Opotow (Eds.), Identity and the Natural Environment. Cambridge, MA: MIT Press. 


\section{THE DEVELOPMENT OF ENVIRONMENTAL MORAL IDENTITY}

Peter H. Kahn, Jr.

University of Washington

One day I met my neighbor, a logger, on a dusty dirt road, near our respective lands, an hour drive from the nearest small town. His name is Horse. He's a big fellow, part White and part Indian. On that day he tells me that he's heading five miles north to where he and his crew are logging on a 30,000-acre cattle ranch. He adds loudly: "Now I ain't hurtin' the environment any. You know, I love this land." I do know. And I knew his dad, too, who had been foreman of another large cattle ranch ten miles east. Decades earlier, as an adolescent, I had on more than one occasion ridden horseback through that land trespassed if truth be told. Horse and I came of age in these mountains. I answer Horse back, "Heck, the trees you're cutting, they're mostly overly mature trees, don't you think?" And he looks pleased that I had remembered the point he made during a conversation last year: that he's harvesting trees that are soon to die anyway and so he's doing no harm. "Horse, you know, I'm starting to feel a bit overly mature myself. I hope no one starts a comin' after me." "Oh hooo," Horse bellows, and he drives north. We were glad to see each other. 
But I remain puzzled. How do people - whose identities appear so deeply connected to the land they love - engage in environmentally harmful activities? Do they really believe that the activity (e.g., logging mature trees) causes no environmental harm? Do economic demands simply trump environmental moral judgments? Or do both the demands and judgments coexist in an uneasy if unequal alliance? What does it mean when such people say that they love the land? Do they love the land only for what it can give to them, or in some way that extends beyond their own immediate self interest?

Such questions have formed part of my research that aims toward an account of the human relationship with nature (Kahn, 1994, 1997ab; 1999; Kahn \& Friedman, 1995, 1998; Kahn \& Kellert, in press). To succeed, or course, any such account must be large in scope and interdisciplinary. It would include, for example, investigations into our evolutionary history within a Darwinian framework: that certain responses to nature have been more adaptive than others (e.g., fear of snakes or an attraction to bodies of water) and thus persist in who we are today (Kellert, 1997; Kellert \& Wilson, 1993; Wilson, 1975, 1984). It would also include social, political, and historical investigations (e.g., Berry, 1997; Nash, 1973; Orr, 1994). My own focus over the years - while attentive to such investigations - has been more on understanding the development of children's environmental moral reasoning and values. For such understandings, when attained, capture that which is at once deeply fundamental to our being and very practical. In his classic essay on the conservation ethic, Leopold (1949/1970) 
argues that environmental education will continue to fail until we help people develop a "love, respect, and admiration for land, and a high regard for its value" (p. 261). "No important change in ethics," Leopold writes, "was ever accomplished without an internal change in our intellectual emphasis, loyalties, affections, and convictions" (p. 246). That is much of what I have been after: understanding, with respect to nature, children's intellectual emphasis, loyalties, affections, and convictions.

Thus I have two goals in this chapter. First, I present some of my central findings on children's environmental moral reasoning. Some of this material I have presented elsewhere. But I take this occasion to raise a particularly puzzling aspect of the cross-cultural data on the relative effects of development and culture in forming an individual's environmental conceptions. Second, I show how this research and theorizing bear on understanding the child's construction of environmental moral identity. I will suggest that through structural development the multiplicities of environmental identity are integrated and transformed into a largely coherent and unified sense of self.

\section{Environmental Moral Reasoning}

Toward conveying a sense of children's environmental moral reasoning, I draw selectively from five collaborative studies. Two studies involved a black population in an economically impoverished community of Houston, Texas. In the first study (which will be referred to as the Houston child study) we 
interviewed 72 children, evenly divided across grades 1, 3, and 5 (Kahn \& Friedman, 1995). ${ }^{1}$ In the second study (the Houston parent study) we interviewed 24 parents from the school which participated in the Houston child study (Kahn \& Friedman, 1998). In the third study (the Prince William Sound study), we interviewed 60 children in Houston across grades 2, 5, and 8, on their moral and ecological reasoning about the 1990 Exxon-Valdez oil spill that occurred in Prince William Sound, Alaska (Kahn, 1997b). In the fourth study (the Amazonia study) we modified the methods from the Houston child study and interviewed in Portuguese 44 5th grade Brazilian children in urban and rural parts of the Amazon Jungle (Howe, Kahn, \& Friedman, 1996). In the fifth study (the Lisboa study) we interviewed in Portuguese 120 children and young adults in grade 5, 8, 11, and college in Lisbon, Portugal (Kahn \& Lourenço, in press).

Methodologically, we employed the "semi-structured" interview which was pioneered by Piaget (e.g., 1929/1969, 1932/1969, 1983) and has been elaborated upon by a large number of more recent researchers (e.g., Damon, 1977; Ginsburg, 1997; Helwig, 1995; Killen, 1990; Kohlberg, 1984; Lourenço, 1990; Smetana, 1995; Turiel, 1983). Some of our interview questions focused on the pollution of a local waterway: of a nearby bayou in Houston; of the Rio Negro in

\footnotetext{
${ }^{1}$ When discussing my collaborative research, I prefer to shift voice from the singular ("I") to plural ("we") to reflect when appropriate the collaborative endeavors.
} 
Amazonia; of the Rio Tejo in Lisboa. Other questions focused on participants' (a) environmental commitments and practices, (b) moral understandings about human actions that affect such everyday natural phenomena as birds, water, plants, insects, open spaces, and air, (c) potentially contradictory environmental judgments, (d) conceptions of what counts as "natural" activity, and (e) conceptions of what it means to live in harmony with nature.

I start with some results from the Houston child study. Keep in mind that the children we interviewed came from one of the most economically impoverished communities in Houston (which I will say more about shortly). Of the children we interviewed, the majority (84\%) said that animals played an important part in their lives, as did plants (87\%) and parks/open spaces (70\%). The majority of children (72\%) talked about environmental issues (such as pollution) with their family, and did things to help the environment, such as recycling (74\%) or picking up garbage $(25 \%)$. Children judged that polluting a bayou would have harmful effects on birds (94\%), water (91\%), insects (77\%), and the view (93\%). Moreover, it is one thing to know that harm is occurring to an entity; it is another thing to care that that harm is going on. Results showed that it would matter to these children if such harm occurred to birds (89\%), water (91\%), insects (77\%), and the view (93\%).

We also analyzed whether children judged the act of throwing garbage in their local bayou as a violation of a moral obligation. We drew here on the domain literature of Turiel (1983, 1998), Nucci (1981, 1996), Smetana (1983, 
1995), and others where a moral obligation is assessed, in part, based on the criterion judgments of prescriptivity (e.g., throwing garbage in a bayou is not all right to do), rule contingency, (the act is not all right to do even if the law says it is all right to do), and generalizability (the act is not all right for people in another country to do, even if people in that country do the act). Based on these and three other criterion judgments, and in consort with children's moral justifications, results showed that the majority of the children believed it was morally obligatory not to throw garbage in a bayou. Developmentally, fewer children in grade 1 (68\%) compared to grades $3(91 \%)$ and $5(100 \%)$ provided such morally obligatory judgments.

In this study, we also characterized children's environmental moral reasoning. In the broadest perspective, two main forms of environmental reasoning emerged from the data: anthropocentric and biocentric.

Anthropocentric reasoning appeals to how effects on the environment affect human beings. Justification categories included appeals to (a) personal interests (e.g., "animals matter to me a little bit because we need more pets and different animals to play with"); (b) aesthetics (e.g., "because I'd get to see all the colors of the plants and the beauty of the whole -- of the whole natural plants"); and (c) the physical, material, and psychological welfare of self and others (e.g., "air pollution goes by and people get sick, it really bothers me because that could be another person's life"). In turn, biocentric reasoning appeals to a larger ecological community of which humans may be a part. Justification categories included 
appeals to the intrinsic value of nature (e.g., "if nature made birds, nature does not want to see birds die") and to the rights of nature or that nature deserves respect (e.g., "they [animals] need the same respect we need").

Isomorphic and Transmorphic Reasoning. Two ways, in particular, emerged from the data for how children established biocentric rights reasoning. One way occurred through establishing isomorphic relationships. Here natural entities (usually animals) were compared directly with humans. For example, one child said: "Fishes, they want to live freely, just like we live freely...They have to live in freedom, because they don't like living in an environment were there is much pollution that they die every day." Thus an animal's desire ("to live freely") is viewed to be equivalent to that of a human's desire, and because of this direct equivalency children reasoned that animals merit the same moral consideration as do humans. A second way occurred through establishing transmorphic relationships. For example, a 5th grade child said:

Fish need the same respect as we need....Fishes don't have the same things we have. But they do the same things. They don't have noses, but they have scales to breathe, and they have mouths like we have mouths. And they have eyes like we have eyes. And they have the same co-ordinates we have....A co-ordinate is something like, if you have something different, then I'm going to have something, but it's going to be the same. Just going to be different. 
This child appears to draw on a word he encountered in some other context to help him explain that while fish are in some respects not the same as people (they don't have noses like people do) that in important functions (such as breathing and seeing) they are the same. Thus he moves beyond a reciprocity based on directly perceivable and salient characteristics to be able to establish moral equivalences based on functional properties.

Isomorphic and transmorphic reasoning should not be confused with anthropomorphic reasoning. In the latter case, an aspect of nature is equated to be like people. Consider, for example, the anthropomorphic reasoning of the following child from the Amazonia study (translated from Portuguese), as she was explaining why the government should stop people from logging the jungle:

It is like me having a leg or an arm cut... Nature is like a person, no, thousands of persons because it isn't just one thing....[A] person is like a tree. If the tree bears fruits, it is the same with people. Taking care of a tree is the same. If you cut a branch off a tree it is like cutting a finger or the foot. To cut a tree down is like doing it to yourself. It is the same to our heart, it is not good. The jungle is like the heart of a person.

Here nature is likened to a human or becomes human in one or more important ways ("Nature is like a person, no, thousands of persons...[A] person is like a 
tree"). In contrast, as noted above, in isomorphic reasoning a moral feature (such as freedom) is deemed important to both nature and humans, and on that basis a moral principle (such as to protect freedom) is applied equally to both nature and humans ("Fishes, they want to live freely, just like we live freely").

Developmentally, the child's understandings of animals appears to start early in childhood. Myers (1998; Myers \& Saunders, in press), for example, provides evidence that even by 3 months of age children begin to develop understandings that animals display four properties that remain constant across many different interactions: agency (a dog decides to eat and acts accordingly), affectivity (a dog appears to enjoy playing with the child), coherence (a dog is able to coordinate its movements in response to the child's actions), and continuity (the dog's repeated interactions become regularized into a relationship with the child). Such understandings, according to Myers, make it possible for children to recognize that animals have their own subjective states and can have correlative interests in interacting with the child ("my dog wants to play with me"). These cognitive underpinnings, in turn, make possible the development of caring for individual animals. Such caring, however, can fall short. After all, what about animals children do not know personally - a dog across town? macaques in Indonesia? Presumably such animals also deserve moral consideration. Thus, my account of the development of children's isomorphic and transmorphic biocentric moral reasoning extends Myers's theorizing insofar as it characterizes increasingly complex levels of moral reasoning that allow older children to construct 
generalized concepts of care: for animals in general and potentially the natural world as a whole.

Isomorphic and transmorphic reasoning may also provide the developmental underpinnings for yet another evolutionarily-shaped relationship with nature. What I have in mind is this. In his book The Others: How Animals Made us Human, Shepard (1996) argues that animals were "among the first objects of classificatory thinking" (p. 97) and that "the human species emerged enacting, dreaming, and thinking animals and cannot be fully itself without them" (p. 4). "Of each species", Shepard proposes, "we can say, 'I am not that -- and yet, just in this one respect, it is like a part of me,' and so on, as though with every 'I am not that one' we keep some bit of them. We take in the animal, disgorge part of it, discover who we are and are not" (p. 72). Thus, in comparison to anthropomorphic reasoning, isomorphic reasoning - and to a larger extent transmorphic reasoning - grants greater independence to the natural world, embracing what Shepard (1996) refers to as "otherness": the partly unknown and wild aspects of nature that "is essential to the discovery of the true self" (p. 5).

Cross-Cultural Similarities. One of the striking features across our five studies was the degree of cross-cultural similarities. For example, by and large participants across studies said that animals, plants, and open spaces played an important part in their lives, were aware of environmental problems, recognized that pollution harmed various natural entities (e.g., birds, water, insects, and the view), would care if such harm occurred, and brought moral obligatory reasoning 
(based on the criteria of prescriptivity, non-contingency of conventional practices, and generalizability) to their environmental judgments.

Even more striking, perhaps, was the degree to which participants' reasoning seemed virtually identical across locations. To provide a sense of the substance here - that the similarities do not merely reflect superficial resemblances - I provide some matched examples of reasoning across locations. I start with an example that speaks to a common if not visceral response people have to a polluted environment:

1A. [The people by the river would be affected because] the smell of the water, it should bother people to open their windows and feel that foul smell....[It would matter to me] because a person shouldn't have to smell dead fish or trash bags full of rotten stuff when she opens the window in the morning. (Lisboa study)

1B. [The air] stinks, 'cause I laid up in the bed the other night. Kept smelling something, knew it wasn't in my house, 'cause I try to keep everything clean. Went to the window and it almost knocked me out. The scent was coming from outdoors into the inside and I didn't know where it was coming from.... Now, who'd want to walk around smelling that all the time? (Houston parent study) 
Such reasons grounded the participants' judgments that it is wrong to throw garbage in a local waterway or to pollute the air.

Other examples speak to the importance of trees in the healthy psychological functioning of human lives:

2A. I live in the country and I find that living in the city is very difficult, it causes stress. For instance, we live on this street full of trees. Anytime that I leave home in the morning, I feel invigorated seeing the trees and their shade, I can breathe, I can hear the birds. Now, if I lived on a street close to Avenida da Republica, I would feel stressed seeing that amount of cars, very few trees. (Lisboa study)

2B. Yesterday, as my son and I were walking to the store and we were walking down Alabama [street] and for some reason, I think they're getting ready to widen the street. And it's a section of Alabama that I thought was so beautiful because of the trees and they've cut down all the trees. And you know it hurts me every time I walk that way and I hadn't realized that my son had paid attention to it, too. So, he asked me, he said, "Mama, why are these, why have they cut down all the trees?" And then he asked me, "Well, if they cut down all the trees everywhere, would that have an effect on how we breathe?" (Houston parent study) 
Thus I do not think it is the case that aspects of everyday nature - trees, plants, open spaces, sunshine, fresh air - are luxuries of the well-to-do; rather, they are psychological necessities that people often recognize. I will expand on this point later.

I provided earlier an example from the Houston child study of transmorphic reasoning. Consider now two virtually identical examples from children in Amazonia and Lisboa:

3A. Even if the animals are not human beings, for them they are the same as we are, they think like we do. (Amazonia study)

3B. [Wild animals are important] because they breathe like we do, and sometimes we think that because they are animals they are not like us, that they don't do certain things. Then we end up seeing that they do. (Lisboa study)

Aristotle (1962) begins Nichomachean Ethics by saying that "the good, therefore, has been well defined as that at which all things aim." He then develops a teleological account of the good, wherein each kind of inanimate object (e.g., a clock) and animate being (e.g., a human) has an ideal way of functioning. Something of this Aristotelian orientation emerged from the data. Consider examples across four studies: 
4A. Yea, because it looks better...Well, I mean without any animals the world is like incomplete, it's like a paper that's not finished. (Prince William Sound study)

4B. Because water is what nature made; nature didn't make water to be purple and stuff like that, just one color. When you're dealing with what nature made, you need not destroy it. (Houston child study)

4C. Because the river was not made to have trash thrown in it, because the river belongs to nature. (Amazonia study)

4D. [Wild animals] are important because if someone created them it is because they have some kind of role. (Lisboa study)

All these participants offer a moral conception of the proper endpoint of nature, and that the good arises with nature reaching that end and being complete.

By emphasizing cross-cultural similarities, I do not want to run roughshod over unique features of each cultural context, and how these features, too, can shape children's environmental commitments and sensibilities. In the Houston child study, for example, $7 \%$ of the children responded to the question of what they thought about in terms of nature with issues pertaining to drugs and human 
violence; and when asked about what environmental issues they talk about with their families, $17 \%$ of the children responded with similar issues. As one $5^{\text {th }}$ grade girl said when merely describing a bayou (a preliminary question in the interview):

It's where turtles live and the water is green because it is polluted. People - some people need to um, some people are nasty. Some people, you know, like some people go down there and pee in the water. MM HMM. Like boys, they don't have no where to pee, and drunkers, they'll go do that, too. OKAY. And sometimes they'll take people down and rape them, and when they finished, they might throw 'em in the water or something. SO, WHAT DOES IT LOOK LIKE? HOW WOULD YOU DESCRIBE IT? A BAYOU? It's big and long and green and it stinks...And turtles live in it.

Indeed, it was this element of human violence and danger that often prevented children in Houston from experiencing nature. For example, consider one of the $1^{\text {st }}$ grade children in the Houston child study, Eboni, who seemed to us least connected to or interested in nature. We asked her, "Do you ever climb trees?" She said no. We asked why. She responded: "Cause it's dangerous. Cause if they fall the grass might have glass and then they fall on they face in the glass and then they'll cut their nose or eyes and they they'll be blind." Eboni told 
us that she never goes to the local park. We asked why. "Because I used to go, now the people go in there and they be throwing glass and they have guns and stuff and they might shoot me." Indeed, Eboni does not even like to play in her back yard. Why? "Nothin' can get me. Like a stranger or something." Thus it is less the case that Eboni has no affiliation with animals, plants, and parks/open spaces, and more that her economically impoverished and violent urban surroundings have made nature largely inaccessible.

\section{The Development of Biocentric Reasoning}

In the above account of environmental moral reasoning, I pay heed to culture. Yet some readers may be thinking: "Well, in all that has been said so far, culture really plays a secondary role, attenuating or modifying what are proposed as more fundamental psychological processes and constructions. Are there not ways that culture plays a primary role?" Perhaps. What I would like to explore now is a puzzling aspect of my data, and whether a cultural explanation can be invoked to solve it.

The puzzle emerged in the following way. Earlier I showed that both anthropocentric and biocentric reasoning emerged in the Houston child study. However, taken across nine questions that we analyzed systematically, only about $4 \%$ of children's reasoning was biocentric. Based on this result, I wondered what we would find if we interviewed children who grew up not in an inner city but in a rural village that lived in daily intimate connection with the land. Would we, 
for example, find a greater proportion of biocentric reasoning? This question was one of several that motivated the Amazonia study. Our results showed, however, that even in the small rural village along the Rio Negro (accessible only by boat), there was no statistical difference in the percentage of biocentric reasoning (about $4 \%$ in Houston; $4 \%$ in Manaus; and $8 \%$ in the remote village).

In interpreting these results, I was inclined to believed that across cultures biocentric reasoning emerges more fully in older adolescents and adults. Thus conducting our next study in Lisboa seemed ideal. For we were able to control not only for language (interviewing in Portuguese), but within the very country that had colonized much of Brazil. Thus, if biocentric forms of reasoning were found to increase with age across our Portuguese population, it would provide evidence to support the developmental hypothesis.

Our results showed that on a few questions (that we had not asked in the previous studies) that biocentric reasoning increased somewhat with age. For example, we asked "Are wild animals important to you, and why or why not?" On this question, results showed the following use of biocentric reasoning: $5^{\text {th }}$ grade, $60 \%$ of justifications were biocentric; $8^{\text {th }}$ grade, $70 \% ; 11^{\text {th }}$ grade, $83 \%$; and college, $82 \%$ ). Still, such biocentric orientations were not pervasive. For across most of the 11 questions where we systematically garnered justification data, the proportion of biocentric reasoning with the older population in Portugal roughly matched the small proportion of biocentric reasoning in the Houston child study and Amazonia study. 
In interpreting these results, I had suggested elsewhere (Kahn, 1999, chap. 10) that there was some qualified support for the developmental hypothesis. I said, for example, that perhaps biocentric reasoning has taken shape structurally by adolescence, but then gets employed only occasionally, depending on the context. As an analogy, imagine if you had a sports car that had the capability of going $110 \mathrm{mph}$. Occasionally you might exercise this capability. But usually the context of driving in the city prevents such activity. Similarly, adolescents and young adults may have developed the capability to engage in biocentric reasoning, but rarely do so.

Such an explanation, however, may misconstrue key ideas that lie at the intersection of biocentric reasoning, development, and culture. Throughout my investigations, I have assumed that there is a single pathway by which biocentric reasoning emerges. But perhaps two pathways actually exist. One pathway may emerge (but for some reason - as shown by the Amazonia study - not in all cases) in cultures that live in daily, intimate contact with the land. Thus, for example, Nelson (1989) reports on the biocentric relationship that the Koyukon of Northern Alaska have with their community of nature: a community that includes not only humans, animals, and plants, but mountains, rivers, lakes, storms - the earth itself. As Nelson (1989) writes: "According to Koyukon teachers, the tree I lean against feels me, hears what I say about it, and engages me in a moral reciprocity based on responsible use. In their tradition, the forest is both a provider and a community of spiritually empowered beings. There is no emptiness in the forest, 
no unwatched solitude, no wilderness where a person moves outside moral judgment and law" (p. 13).

In turn, a second pathway by which a culture can develop a biocentric orientation may depend less on daily, intimate contact with the land, and more on modern philosophical moral discourse. Here there is some historical precedence that such moral discourse leads to extending moral standing to an ever widening range of entities. For example, over the last 150 years in the United States, moral rights have accrued to Blacks, women, and children; and some argue it is just a matter of time before they accrue to animals and nature in general. As Stone (1986) writes: "each time there is a movement to confer rights onto some new 'entity,' the proposal is bound to sound odd or frightening or laughable. This is partly because until the rightless thing receives its rights, we cannot see it as anything but a thing for the use of 'us' - those who are holding rights at the time...I am quite seriously proposing that we give legal rights to forests, oceans, rivers and other so-called 'natural objects' in the environment - indeed, to the natural environment as a whole" (pp. 84-85).

If this "dual-pathway" account has merit, then are the biocentric conceptions that emerge by means of these two pathways the same? I do not know. To answer this question, one would need psychological research with children, adolescents, and adults in native cultures, such as perhaps the Koyukon, that have a clear biocentric ethos. A major difficulty of conducting such research, of course, is that such cultures are disappearing quickly, absorbed by increased 
globalization, and changed - apparently irreversibly - by the introduction of advanced technologies and Western consumer desires.

\section{Environmental Moral Identity}

The term identity seems fraught with difficulties (Holland, 1997; Shweder \& Bourne, 1984; Thoits \& Virshup, 1997; McAdams, 1997). As Ashmore and Jussim (1997) write: "Self and identity are not simple concepts...These words point to large, amorphous, and changing phenomena that defy hard and fast definitions..." (p. 5). Indeed, one of the most difficult problems for scholars of identity is reconciling two opposing ideas, of whether identity as a construct is multiple or unified. On the side of multiplicity is the obvious fact that each one of us has many roles. A single person can be, for example, a father, lover, poker player, gourmet cook, and accountant. Indeed, William James says that a person "has many social selves as there are individuals who recognize him" (quoted in Rosenberg, 1997, p. 23). On side of unity, virtually all of us feel like our sense of identity remains reasonably stable over time.

The above studies on children's environmental moral reasoning help explicate these two seemingly contradictory conceptions of identity.

Identity as Multiplicity. Children provided a wide range of environmental justifications, including those based on human welfare, personal interests, landscape aesthetics, the intrinsic value of nature, and the rights of animals. Each of these justifications themselves took various forms which could be coded, and 
these forms in turn had nuances that could be captured qualitatively. For example, considerations for human welfare can involve three forms. One form is physical welfare ("[It's wrong to throw garbage in the bayou] because if the water is dirty, I might get sick" - the Houston Child study). A second is material welfare ("[It's wrong to throw garbage in the water because] from an economic point of view the water would be captured and sent to a central plant where it would be treated. Who is paying for the process to clean the water? Isn't it us? So, we are causing harm to ourselves" - the Lisboa study). A third form is psychological welfare ("[Gardens are important] because the city is a place that causes great stress and it gives a chance to someone to go to a place that is near, and to be in contact with nature, to stay calm" - the Lisboa study).

As shown earlier, sometimes in response to a single question children drew on multiple justifications. Other times different questions pulled forth one form of reasoning over another. The upshot is that even during the early years children do not have a monolithic orientation in reasoning about the natural world.

Different reasons, of course, can justify different courses of action. In such cases, how do children adjudicate seemingly contradictory considerations? Our Lisboa data bear directly on this question. In that study, we asked participants whether air pollution was a problem in Lisboa. Ninety-eight percent of the participants said yes. Then we asked whether driving a car increases the air pollution. One hundred percent of the participants said yes. In this context, we 
then asked a pivotal question: "Do you think it is all right or not all right that a person drives his or her own car to work every day?" For those participants who said that it was all right, we then countered with the probe: "But how is it all right to drive the car if, as you said before, that increases the air pollution?" For those participants who said it was not all right, we then countered with the probe: "But how could this person arrive at his or her place of work? Would that be practical?" Results showed that, in some form or another, $81 \%$ of the participants believed it was all right for a person to drive his or her car to work. But the reason I say "in some form or another" is that in various ways participants often qualified their evaluations, and sought to coordinate their judgments about pollution with other personal and moral considerations of import. Specifically, we were able to ascertain three overarching forms by which participants coordinated their judgments concerning the air pollution caused by driving a car with the permissibility of driving: overriding, contextual, and contradictory. In an overriding coordination, one consideration simply overrides other considerations. For example, in supporting a judgment that driving a car is fundamentally not justified, one participant said: "I think that is totally not all right. Because I think that in Lisboa there is good public transportation...that comes at reasonable frequency and that is not expensive." But it is equally possible to use an overriding coordination to argue that driving a car is fundamentally permissible. For example, another participant said: "I think that it is right. Because one needs this asset to go to work, so he won't have to face long 
lines, like the ones for the buses, so he won't waste so much time." Although these two evaluations differ, the nature of the coordination is the same insofar as each participant upholds a single generalized position. In a contradictory coordination, contradictory positions are upheld. For example, one participant said: "It's right because there are a lot of people who don't have public transportation to go to their jobs...Well, it's a contradiction, but it is that way." This participant says "it's a contradiction" because she had just established that the action in question was not all right. In a contextual coordination, the judgment is dependent on the specific context. For example, one participant said: "It depends. If the place of work is very far away and there is no other way of transportation, then one has to take [one's car]. But if there are other ways of transportation that cause less pollution, I think that people should go [that way]....One could also go by bicycle, that helps exercise and doesn't cause pollution."

I have been suggesting that environmental identity embraces aspects of multiplicity by the very diversity of reasoning that children and young adults across diverse cultures bring to environmental issues. By implication, my perspective (and supporting data) speaks against stereotyping a person or a people. I do not think it can be said, for example, that "loggers are all this way" or that "Green Peace activists are all another way" (cf. Kempton, Boster, \& Hartley, 1995). Of course, this point may seem rather obvious to the reader. But 
a more subtle form of stereotyping occurs in both popular and academic discourse.

As a case in point, consider Inglehart's (1995) study of data from the 1990-93 World Values survey, carried out in 43 countries. From his analysis, Inglehart argued that public concern for environmental quality is stronger in wealthy nations than in poor nations, and that environmentalism is a product of a "postmaterialist culture shift." Inglehart's argument in effect follows Maslow's (1975) theory of a hierarchy of needs: that "someone whose needs for food, shelter and physical security are barely met is not likely to spare the energy physical or emotional - to maintain concern about [environmental issues]" (Hershey and Hill, 1977-78, quoted in Mohai, 1990, p. 747).

Inglehart's study set off vigorous debate in the political science and sociological literature (e.g., Kidd \& Lee, 1997; Martínez-Alier, 1995; Pierce, 1997). One response, in particular, I want to highlight. Namely, Brechin (1999) sought to refute Inglehart's claim by conducting a study on citizen attitudes towards the environment from twelve relatively wealthy countries and twelve relatively poor ones. Brechin found no statistical differences between the two groups on questions concerning symbolic global environmental problems. For example, he found a "biocentric-postmaterialist concern for other living species" across both groups (p. 807). Most generally, Brechin found no support for the postmaterialist claims, which he views as incoherent when applied crossculturally on the national level (cf. Brechin \& Kempton, 1994). 
Brechin thus brings to bear on the sociological level the very idea I have sought to develop on the psychological level: that people even in economically impoverished communities have rich and diverse appreciation for nature, and moral responsiveness to its well-being. Granted, such moral regard for nature may not take forms commonly associated with "environmentalism" - such as high regard for wilderness areas - although it might. But such moral regard for nature extends well beyond mere interest in combating threats of pollution to one's local community.

Identity as Unity. While children employ rich and diverse forms of reasoning about the natural environment, they also hold to environmental ideas that may change little over time. Drawing on the moral developmental literature (Turiel, 1998), two such ideas can be characterized in terms of assumptions of how the world works: ecological assumptions and metaphysical assumptions.

I sketched an ecological assumption in the opening vignette about my neighbor Horse and his view that logging overly mature trees causes no environmental harm. Similar assumptions emerged from the Lisboa data. For example, consider two responses from college participants:

To cut [trees] for the sake of cutting, no. To cut with a purpose, and using it in a way that is profitable to people over there...is also correct.

But...instead of cutting down any tree, we cut only the ones that are mature, fully grown. That way it wouldn't be a big problem. 
However, sometimes [cutting trees down] is not deforestation itself. I am talking about cutting trees down, it can be good for the forest, if there are small trees and such, if there is management of that forest, for sure the forest is going to get better. The little ones can't grow because the big ones cast a shadow [over them].

Like Horse, these participants assume that the health and integrity of ecological systems (and specifically forests) do not depend on the existence of mature trees (e.g., for genetic stock) and their eventual death and decay.

Many other such assumptions pervade our societal discourse about environmental issues. Some people assume, for example, that carbon emissions contribute to global warming; others do not. Some people assume that drilling for oil in the Artic Refuge will cause environmental harm; others do not. Some people assume that agriculture based on genetically altered plants will harm farmlands and ecosystems; others do not. Because ecological assumptions are, at least in principle, open to empirical validation, they provide a means by which environmental science education can change aspects of individuals' environmental identity.

The same cannot be said so readily about metaphysical assumptions. The basic idea here has been worked out well in an on-going debate in the moral developmental literature. On the one side, Shweder, Mahapatra, and Miller 
(1987) have argued that there exist divergent if not incommensurable moral perspectives between Hindu and Western cultures. To make their case, Shweder at al. have drawn from their extensive interviews with devout Hindus in India. For example, Shweder et al. found that devout Hindus believe that it is immoral for a widow to eat fish; and surely (Shweder and his colleagues argue) few people in the United States hold to a similar view. On the other side, Turiel, Killen, and Helwig (1987) have argued that what might appear as moral diversity between cultures often involves differences on non-moral dimensions. For example, in their reinterpretation of Shweder et al.'s above example, Turiel et al. found that devout Hindus believed that harmful consequences would follow from a widow who ate fish (the act would offend her husband's spirit and cause the widow to suffer greatly). While such metaphysical assumptions - that spirits exist and can be offended by earthly activity - may differ from those in Western culture, the underlying moral concern for the welfare of others appears congruent across cultures. (For a discussion of these issues, see Kahn, 1991; Kahn \& Lourenço, 1999; Turiel, 1998, in press; Wainryb, 1993, 1995).

In my own research, I have not systematically sought to elicit individuals' environmental metaphysical assumptions. Nonetheless, on occasion such assumptions have emerged in the course of my interviews with children. Sometimes these assumptions came almost verbatim from Biblical texts. For example, one child from the Houston child study offered this response to why he did not eat ham: "[Because] God took the demon out of the man and put the 
demon in the pig, and that's why since then I never ate ham or anything like that." Other times, the metaphysical assumptions were embedded in teleological reasons for why nature has intrinsic value. For example, one child from the Lisboa study argued that wild animals "are important because if someone created them it is because they have some kind of role." Notice that unlike ecological assumptions, metaphysical assumptions are not open to empirical validation, at least in ways understood by Western science. It is not easy, after all, to prove or disapprove that a creator exists, let alone to divine the Divine's intention.

$\underline{\text { Conclusion }}$

I started this chapter by asking how people, whose identities appear so deeply connected to the land they love, can engage in environmentally harmful activities. My answer has built from a seemingly contradictory conception of identity: that it is at once multiple and unified.

In terms of its multiplicity, I have shown how children bring diverse considerations into their environmental reasoning, including those based on personal interests, human welfare, aesthetics, teleology, intrinsic value of nature, and rights and respect for nature. Children also can embrace competing if not contradictory claims (including those that I have characterized as overriding, contradictory, and contextual). In terms of its unity, I have shown how children employ coherent orientations or constellations of orientations across a diverse 
range of environmental topics. In addition, children across diverse cultures appear to engage in remarkably similar environmental moral reasoning.

From the standpoint of developmental psychological theory, does it make sense to talk about environmental identity in terms of both multiplicity and unity? I think so. When a rock falls on a child's head, it does not matter the culture, it physically hurts; and from such interactions children construct notions of physical causality. Or if a child from any culture pulls on a dog's tail hard enough, the dog will object (run away, bark, or even bite); and from such interactions children construct notions of animal welfare. These are but simple examples to illustrate a long-recognized structural-developmental mechanism that operates on both the microgenetic and macrogenetic level (Baldwin, 1897/1973). Through interaction with nature, artifacts, and other people, children construct increasingly adequate understandings of the world. Moreover, through the course of child development earlier forms of knowledge do not so often disappear as they are reworked, transformed, into more sophisticated structures. Recall, for example, that transmorphic reasoning subsumes the sophistication of an isomorphic perspective (that finds similarities between humans and animals), but then does something more with it (coordinates similarities with differences). My point is that the underlying cohesion in cognitive structures helps create the sense of unity in identity at any given developmental point in time, while the transformations of the cognitive structures help create our sense of a changing identity over time. 
Finally, I would like to return to one of the central findings from my collaborative research: that children across diverse cultures engaged in remarkably similar environmental moral reasoning. One explanation for this finding - as I allude to above with the illustration of the falling rock - is that there are universal and invariant aspects of nature itself that give rise to and bound children's environmental constructions. If this explanation is correct, then it follows that while culture plays a fundamental role in the construction of an individual's environmental identity, it is not an unbounded role. Indeed, perhaps less of a role than cultural theorists might suggest. 


\section{$\underline{\text { References }}$}

Aristotle (1962). Nichomachean ethics (M. Ostwald, Trans.). Indianapolis, Indiana: Bobbs-Merrill.

Baldwin, J. M. (1973). Social and ethical interpretations in mental development. New York: Arno. (Original work published 1897)

Berry, W. (1977). The unsettling of America: Culture and agriculture. New York: Avon.

Brechin, S. R. (1999). Objective problems, subjective values, and global environmentalism: Evaluating the postmaterialist argument and challenging a new explanation. Social Science Quarterly, 무, 793-809.

Brechin, S. R., \& Kempton, W. (1994). Global environmentalism: A challenge to the postmaterialism thesis? Social Science Quarterly, $\underline{75}, 245-269$.

Damon, W. (1977). The social world of the child. San Francisco: Jossey-Bass. Ginsburg, H. P. (1997). Entering the child's mind: The clinical interview in psychological research and practice. Cambridge, England: Cambridge University Press.

Helwig, C. C. (1995). Adolescents' and young adults' conceptions of civil liberties: Freedom of speech and religion. Child Development, $\underline{66}, 152-$ 166.

Hershey, M. R., \& Hill, D. B. (1977-78). Is pollution "a White thing?": Racial differences in preadults' attitudes. Public Opinion Quarterly, 41, 439-458. 
Holland, D. (1997). Selves as cultured: As told by an anthropologist who lacks a soul. In R. D. Ashmore and L. Jussim (Eds.), Self and identity (pp. 160190). New York: Oxford University Press.

Howe, D., Kahn, P. H., Jr., \& Friedman, B. (1996). Along the Rio Negro: Brazilian children's environmental views and values. Developmental Psychology, 32, 979-987.

Inglehart, R. (1995). Public support for environmental protection: Objective problems and subjective values in 43 societies. PS: Political Science \& $\underline{\text { Politics, }} \underline{28}(1), 57-72$.

Kahn, P. H., Jr. (1991). Bounding the controversies: Foundational issues in the study of moral development. Human Development, 34, 325-340.

Kahn, P. H., Jr. (1992). Children's obligatory and discretionary moral judgments. Child Development, $\underline{63}$, 416-430.

Kahn, P. H., Jr. (1994). Resolving environmental disputes: Litigation, mediation, and the courting of ethical community. Environmental Values, $\underline{3}, 211$ 228.

Kahn, P. H. Jr. (1997a). Developmental psychology and the biophilia hypothesis: Children's affiliation with nature. Developmental Review, 17, 1-61.

Kahn, P. H., Jr. (1997b). Children's moral and ecological reasoning about the Prince William Sound oil spill. Developmental Psychology, 33, 10911096. 
Kahn, P. H., Jr. (1999). The human relationship with nature: Development and culture. Cambridge, MA: MIT Press

Kahn, P. H., Jr., \& Friedman, B. (1995). Environmental views and values of children in an inner-city Black community. Child Development, $\underline{66}, 1403-$ 1417.

Kahn, P. H., Jr., \& Friedman, B. (1998). On nature and environmental education: Black parents speak from the inner city. Environmental Education $\underline{\text { Research, }} \underline{4}, 25-39$.

Kahn, P. H., Jr., \& Kellert, S. R. (in press). (Eds.) Children and nature: Psychological, sociocultural, and evolutionary investigations. Cambridge, MA: MIT Press.

Kahn, P. H., Jr., \& Lourenço, O. (1999). Reinstating modernity in social science research -- or -- The status of Bullwinkle in a post-postmodern era. Human Development, $\underline{42}, 92-108$.

Kahn, P. H., Jr., \& Lourenço, O. (in press). Air, water, fire, and earth: A developmental study in Portugal of environmental conceptions and values. Environment and Behavior.

Kellert, S. R. (1997). Kinship to mastery: biophilia in human evolution and development. Washington, DC: Island Press.

Kellert, S. R., \& Wilson, E. O. (Eds.). (1993). The Biophilia hypothesis. Washington, DC: Island Press. 
Kempton, W., Boster, J. S., \& Hartley, J. A. (1995). Environmental values in American culture. Cambridge, MA: The MIT Press.

Kidd, Q., \& Lee, A. (1997). Postmaterialist values and the environment: A critique and reappraisal. Social Science Quarterly, 78(1): 1-15.

Killen, M. (1990). Children's evaluations of morality in the context of peer, teacher-child, and familial relations. Journal of Genetic Psychology, 151, $395-410$.

Kohlberg, L. (1984). Essays in moral development: Vol. II. The psychology of moral development. San Francisco: Harper \& Row.

Leopold, A. (1970). A Sand Country Almanac. New York: Ballantine Books. (Original work published 1949)

Louden, R. B. (1984). On some vices of virtue ethics. American Philosophical Quarterly, 21, 227-235.

Lourenço, O. (1990). From cost-perception to gain-construction: Toward a Piagetian explanation of the development of altruism in children. International Journal of Behavioral Development, 13, 119-132.

Martinez-Alier, J. (1995). Commentary: The environment as a luxury good or too poor to be green. Ecological Economics, 13(1), 1-10.

Maslow, A. H. (1975). Motivation and personality. New York: Viking. McAdams, D. P. (1997). The case for unity in the (post)modern self: A modest proposal. In R. D. Ashmore and L. Jussim (Eds.), Self and identity (pp. 46-78). New York: Oxford University Press. 
Mohai, P. (1990). Black environmentalism. Social Science Quarterly, $\underline{4}$, 744765.

Myers, G. (1998). Children and animals: Social development and our connections to other species. Boulder, CO: Westview Press.

Myers, G., \& Saunders, C. D. (in press). Animals as links toward developing caring relationships with the natural world. To appear in P. H. Kahn, Jr. \& S. R. Kellert (Eds.), Children and nature: Psychological, sociocultural, and evolutionary investigations. Cambridge, MA: MIT Press.

Nash, R. (1973). Wilderness and the American mind. New Haven and London: Yale university Press.

Nelson, R. (1993). Searching for the lost arrow: Physical and spiritual ecology in the hunter's world. In S. R. Kellert \& E. O. Wilson (Eds.), The Biophilia hypothesis (pp. 201-228). Washington, DC: Island Press.

Nucci, L. P. (1981). The development of personal concepts: A domain distinct from moral and societal concepts. Child Development, $\underline{52}, 114-121$.

Nucci, L. (1996). Morality and the personal sphere of actions. In E. S. Reed, E. Turiel, \& T. Brown (Eds.), Values and knowledge (pp. 41-60). Mahwah, NJ: Lawrence Erlbaum.

Orr, D. W. (1994). Earth in Mind. Washington, DC: Island Press.

Piaget, J. (1960). The child's conception of the world. New Jersey: Littlefield, Adams \& Co. (Original work published 1929) 
Piaget, J. (1969). The moral judgment of the child. Glencoe, IL: Free Press. (Original work published 1932)

Piaget, J. (1983). Piaget's theory. In W. Kessen (Ed.), P. H. Mussen (Series Ed.), Handbook of child psychology: Vol. 1. History, theory, and methods (4th ed., pp. 103-128). New York: Wiley.

Pierce, J. C. (1997). The hidden layer of political culture: A comment on "postmaterialist values and the environment: A critique and reappraisal." Social Science Quarterly, $\underline{78}(1), 30-35$.

Rosenberg, S. (1997) Multiplicity of selves. In R. D. Ashmore and L. Jussim (Eds.), Self and identity (pp. 23-45). New York: Oxford University Press.

Shepard, P. (1996). The others: How animals made us human. Washington, DC: Island Press.

Shweder, R. A., \& Bourne, E. J. (1984). Does the concept of person vary crossculturally? In R. A. Shweder \& R. A. Levine (Eds.), Culture theory: Essays on mind, self, and emotion (pp. 158-199). Cambridge: Cambridge University Press.

Shweder, R. A., Mahapatra, M., \& Miller, J. B. (1987). Culture and moral development. In J. Kagan \& S. Lamb (Eds.), The emergence of morality in young children (pp. 1-82). Chicago: University of Chicago Press.

Smetana, J. G. (1983). Social-cognitive development: Domain distinctions and coordinations. Developmental Review, $\underline{3}, 131-147$. 
Smetana, J. G. (1995). Morality in context: Abstractions, ambiguities and applications. In R. Vasta (Ed.), Annals of Child Development (Vol. 10, pp. 83-130). London: Jessica Kingsley.

Stone, C. D. (1986). Should tress have standing? - Toward legal rights for natural objects. In D. VanDeVeer and C. Pierce (Eds.), People, penguins, and plastic trees (pp. 83-96). Belmont, CA: Wadsworth. (Original work published 1974)

Thoits, P. A., \& Virshup, L. K. (1997). Me's and we's: Forms and functions of social identities. In R. D. Ashmore and L. Jussim (Eds.), Self and identity (pp. 106-133). New York: Oxford University Press.

Turiel, E. (1983). The development of social knowledge. Cambridge, England: Cambridge University Press.

Turiel, E. (1998). Moral development. In N. Eisenberg (Ed.), Social, Emotional, and Personality Development (pp. 863-932). Vol. 3 of W. Damon (Ed.) Handbook of child psychology. $5^{\text {th }}$ ed. New York: Wiley.

Turiel, E. (in press). The culture of morality: Social development and social opposition. Cambridge, England: Cambridge University Press.

Turiel, E., Killen, M., \& Helwig, C. C. (1987). Morality: Its structure, functions and vagaries. In J. Kagan and S. Lamb (Eds.), The emergence of morality in young children (pp. 155-244). Chicago: University of Chicago Press.

Wainryb, C. (1993). The application of moral judgments to other cultures: Relativism and universality. Child Development, $\underline{64}$, 924-933. 
Wainryb, C. (1995). Reasoning about social conflicts in different cultures: Druze and Jewish children in Israel. Child Development, $\underline{66}, 390-401$.

Wilson, E. O. (1975). Sociobiology: The new synthesis. Cambridge: Harvard University Press.

Wilson, E. O. (1984). Biophilia. Cambridge, MA: Harvard University Press. 